\title{
Peripherally inserted central venous catheter (PICC) in outpatient and inpatient oncological treatment
}

\author{
Dorothea Mielke ${ }^{1} \cdot$ Andrea Wittig $^{2} \cdot$ Ulf Teichgräber $^{3}$ (D) \\ Received: 20 June 2019 / Accepted: 23 December 2019 / Published online: 22 January 2020 \\ (C) The Author(s) 2020
}

\begin{abstract}
Purpose So far there is little evidence on peripherally inserted central venous catheter (PICC) in radiation oncology patients maintaining the access during the periods of ambulatory and hospital treatment.

Methods A total of 522 PICC placements in 484 patients were performed between 11/2011 and 07/2016 at the Department of Radiation Oncology and analysed retrospectively for complications and treatment- and patient-related factors during ambulatory and hospital inpatient use. On initial hospitalization, all patients received a multimodal radio-oncological treatment consisting of radiation and intravenous therapy administered via the PICC.

Results A total of 18,292 catheter days were documented. Median follow-up from catheter insertion to their removal was 37 days (1-97). The overall complication rate was 4.1 per 1000 catheter days $(n=75,14.4 \%)$. Complications were similar between the cohort of outpatient 3.6 per 1000 catheter days and the cohort of inpatient 4.8 per 1000 catheter days (OR 0.976 ; $95 \%$ CI [0.598; $1.619] ; p=0.924)$. Severe bloodstream infections occurred at a rate of 0.60 per 1000 catheter days $(n=11,2.1 \%)$, deep vein thrombosis at a rate of 0.82 per 1.000 catheter days $(n=15,2.9 \%)$ and local inflammation at a rate of 1.26 per 1.000 catheter days $(n=23,4.4 \%)$. Only immunotherapy could be identified as an independent risk factor for complications (OR 5.6; 95\% CI [2.4; 13.1]; $p<0.001)$.

Conclusion Using PICC in outpatients is not associated with an elevated risk of complications. Particular attention should be payed to early identification of PICC associated bloodstream infections. Immunotherapy is an independent risk factor for local skin complication.
\end{abstract}

Keywords Radio-oncology $\cdot$ PICC $\cdot$ Complications $\cdot$ Outpatient and inpatient

Electronic supplementary material The online version of this article (https://doi.org/10.1007/s00520-019-05276-0) contains supplementary material, which is available to authorized users.

Ulf Teichgräber

ulf.teichgraeber@med.uni-jena.de

Dorothea Mielke

dorothea.mielke@srh.de

Andrea Wittig

Andrea.wittig@med.uni-jena.de

1 Department of Radiation Oncology, Universitätsklinikum Jena, Bachstr.18, 07743 Jena, Germany and SRH Wald-Klinikum Gera GmbH Straße des Friedens 122, 07548 Gera, Germany

2 Department of Radiation Oncology, Universitätsklinikum Jena, Bachstr.18, 07743 Jena, Germany

3 Institut für Diagnostische und Interventionelle Radiologie, Universitätsklinikum Jena, Am Klinikum 1, 07747 Jena, Germany

\section{Introduction}

Peripherally inserted central catheters (PICCs) are nontunnelled central venous access devices designed for intermediate to long-term use, which are usually placed via a peripheral upper arm vein (i.e. basilica, brachial or cephalic vein) with the catheter tip placed at the cava arterial junction. The average time in situ ranges between 1 week and 6 months; longevity of up to 1 year has been described [1-3]. The technique of a peripherally inserted central venous catheter dates back to the 1970s first used for the parenteral feeding [4]. First attempts were originally accompanied by many complications [5]. Due to medical und technological progress, many of the initial problems have been solved, although some of them (i.e. thrombosis, blood stream infections, etc.) are yet present. The use of PICC has been adequately studied in ICU patients and paediatrics $[1,3,6-8]$. 
Cancer patients receiving therapy often require an appropriate central venous access to administer chemotherapy, immunotherapy and also for parenteral nutrition, haemodynamic monitoring, blood sampling and supportive therapy [9-11]. Several types of central venous catheter are available at present depending on indication, medical and patient needs. The totally implantable central venous catheter (port catheters) provides long-term (months to years) intermittent access; thin-lumen, non-tunnelled access devices (i.e. central venous catheters $(\mathrm{CVC}))$ are intended only for the short-term use $(<$ 14 days) in hospitalized patients [12, 13]. PICC has been established preferably as medium-term access [2, 3, 13-15].

As a result of medical progress, more and more therapeutic procedures can be performed on an outpatient basis. Moreover, there is an overt political intent to maximize the utilization of outpatient health services because of efficiency in all areas of medicine.

In this context, there is a demand for a safe, reliable, costeffective and easy-to-use central venous access in cancer patient that can be universally used in both the hospital and community settings.

It is not clear whether PICC meets mentioned requirements and whether it is a favourable alternative to repeated CVC insertion or a more invasive port implantation. Indeed, the evidence for PICC in patients undergoing radio-oncological treatment is low. No reliable clinical data are available on safety of PICC in cancer patient switching from in- to outpatient care during multimodal radiotherapy.

\section{Objectives}

The aim of this study was to investigate practical feasibility and safety profile of PICC in cancer patients receiving radiotherapy in out- and inpatient settings.

\section{Patients and methods}

A total of 522 PICC placements in 484 patients were performed between 11/2011 and 07/2016 at the Department of Radiation Oncology of the Territory University Hospital Jena, Germany, and analysed retrospectively for complications and treatment- and patient-related factors during ambulatory and hospital inpatient use.

The PICC insertion must have been referred by an experienced medical specialist in Radiation Oncology to the Interventional Radiology Vascular Access Service. No cases of foreign PICC indication or insertion were included.

All cancer patients $>18$ years were enrolled if PICC was successfully placed for chemotherapy, immunotherapy, total parenteral nutrition, antibiotics or blood sampling.

A total of 545 PICCs signed up for insertion were eligible for the initial selection.
About 23 cases (4.2\%) were excluded because of cancelled PICC placement due to lack of patient's informed consent, wrong medical indication due to, e.g. already existing central venous port system, missing medical follow-up documentation or technical placement failure.

\section{PICC insertion and maintenance}

All PICC insertions were performed by an interventional radiologist following evidence-based institutional protocols (Institute for Diagnostic and Interventional Radiology at University Hospital of Jena) with maximal barrier and antisepsis precautions.

Prior applying a tourniquet, a preprocedural ultrasound evaluation of the potential access site was carried out to identify surrounding anatomical structures, to find an appropriately-sized vessel and to ensure its patency. To minimize the risk of PICC-associated venous thrombosis, the catheter-to-vein ratio of $45 \%$ or less should be warranted [16]. We implanted only double lumen 5-6 French PICCs (Bard Access Systems, Salt Lake City, USA; Navilyst Medical, Marlborough, USA). The placement of the catheter at the upper mid-arm into the V. basilica or V. brachialis was performed "real-time" ultrasound-guided using the Seldinger technique under local anaesthesia [15]. The right-sided insertion was preferred unless of medical contraindications.

A small needle was used accessing the target vein followed by introduction of a soft-tipped guidewire to determine the necessary PICC length. The needle was then removed and peel-away sheath was inserted over the guidewire. After the guidewire and dilator were removed, the catheter was threaded through introducer under fluoroscopic control to final tip location at the cavoatrial junction $[14,17]$.

Fixation to the skin was performed in all patients with sutureless devices (e.g. StatLock ${ }^{\circledR}$ Catheter Stabilization Device, Bard Access Systems) and chlorhexidineimpregnated transparent waterproof films (e.g. Tegaderm ${ }^{\mathrm{TM}}$ CHG, 3 M Deutschland $\mathrm{GmbH}$ ) due to our hospital standard operating procedures (Image 1).

Maintenance and drug delivery were accomplished by trained medical personnel in accordance with hygiene recommendations [2]. Nursing protocol for PICC care included redressing of the catheter exit site with an aseptic technique, flushing and locking of PICCs with prefilled $10 \mathrm{ml}$ normal saline syringes by pulsatile method before and after every intravenous drug delivery

$[18,19]$. In both in- and outpatients, PICC maintenance was performed at weekly intervals.

In hospitalized patients, PICC was visually inspected for possible complications at every drug delivery. Ambulant patients got weekly PICC care in our outpatient department. No heparin locking was used, as it is associated with significant risks and no apparent benefit [18]. 


\section{Time course of radiation therapy and PICC usage}

The PICC insertion was usually carried out as outpatient procedure at the Institute for Diagnostic and Interventional Radiology at Jena University Hospital.

Shortly thereafter patients were hospitalized for initiation of the multimodal radio-oncological treatment. Chemotherapy, immunotherapy, parenteral nutrition or a combination of these was usually administered there via the PICC.

Subsequently patients were discharged and received the rest of radiation therapy on outpatient basis with the PICC still in situ. This venous access was then used for regular blood draws, drug administration and parenteral nutrition.

Readmissions were mostly planned for the next course of chemotherapy but also unplanned because of PICC or oncological complications.

This described switch between outpatient and inpatient treatment happened up to six times (median, 2; range, 0-6 times) depending on the individual radio-oncological treatment concept.

A small part of patients $(n=109,20,9 \%)$ remained hospitalized during the whole oncological therapy.

PICC was removed at accomplishing the treatment or in the case of a relevant complication approved by a treating radiooncologist.

\section{Statistical analysis}

Both groups of individuals treated as in- and outpatient were compared by means of univariate and multivariate analysis. The $\chi^{2}$ test or Fisher's exact test was used to compare categorical variables; Mann-Whitney U test was used to compare continuous variables. The multivariate analysis was performed as a regression analysis of the generalized linear models.

All $P$ values were two-tailed, and $P<0.05$ was considered statistically significant.

The analysis of complication rates in the in- and outpatient group was carried out as a binary logistic regression analysis using a generalized estimation equation, adjusted for insertion time. All analyses were performed using SPSS (Version 20.0).

\section{Results}

The overall technical success rate of PICC insertion was $98.7 \%$. A total of 522 PICC systems were used for data evaluation in the follow-up period. The baseline characteristics of the patients included are described in Table 1 . The total indwelling time was documented to be 18,292 catheter days. The cumulative follow-up during hospitalization was 7954 days $(43.5 \%)$ and 10,338 days $(56.5 \%)$ during ambulant treatment. During the follow-up period, a total of 75 PICCassociated complications resulting in removal of the catheter were documented. The PICCs were mainly used for the application of chemotherapy $(n=360 ; 69 \%)$, immunotherapy $(n=$ $31 ; 5.9 \%)$, parenteral nutrition $(n=42 ; 8.0 \%)$, intensified supporting care $(n=22 ; 4.2 \%)$ and combination of whose $(n=67 ; 12.9 \%)$. Table 2 shows complication rate depending on type of use.

The overall complication rate was 4.1 per 1000 catheter days.

The complication rate in the outpatient group was 3.6 per 1000 catheter days vs. 4.8 per 1000 catheter days in inpatient group. There was no difference in the number of complications in these two cohorts (OR $0.976 ; 95 \%$ CI $[0.598 ; 1.619]$; $p=0.924)$.

The median indwelling time of PICC was 37 days (1-97). By day 35 , about $88.3 \%$ of PICCs were still in use by outpatients had no complications. About $81.5 \%$ of the actively used catheters in the inpatient group were still free of complications after 34 days of indwelling time (Fig. 1). As shown in Table 3, the most frequent observed complications were local inflammation at the insertion site $(n=23 ; 4.4 \%)$, venous thrombosis $(n=15 ; 2.9 \%)$, bloodstream infection $(n=11 ; 2.1 \%)$ as well as occlusion $(n=11 ; 2.1 \%)$ of the PICC.

Most of the PICC complications $(n=61,11,7 \%)$ were considered as minor adverse events, which resulted solely in venous access removal. Major adverse events $(n=14,2.7 \%)$ leading to (prolonged) hospitalization were mostly due to PICC-associated bloodstream infection. They occurred at a rate of 0.7 per 1000 catheter days. Microorganism isolated from the PICC tip, as well as $S$. aureus bacteraemia, could be confirmed in $2(0.4 \%)$ of $13(2.5 \%)$ cases. In other cases, patients presenting septic symptoms had negative microbiological blood samples. One case was diagnosed with a pulmonary artery embolism.

In a multivariate analysis, only immunotherapy could be identified as an independent risk factor for complications (OR $5.6 ; 95 \%$ CI $[2.4 ; 13.1] ; p<0.001)$.

\section{Discussion}

Many cancer patients receiving radiotherapy require central venous access. The choice of the device is usually made by treating physician on the basis of medical criteria, e.g. kind of intended application and duration, availability, patient's condition and guidelines.

So far, the assortment of available central venous devices for radiotherapy is limited in Germany. Currently, non-tunnelled CVCs are only used in hospitalized patients and ports are often preferred in outpatient care. The tunnelled CVC are less common central venous access types. They have low level of evidence in cancer patients receiving radiotherapy. The majority of tunnelled CVC types have been designed for highly specific medical applications (e.g. Demers ${ }^{\circledR}$ catheters for dialysis). Broviac ${ }^{\circledR}$ and Hickman ${ }^{\circledR}$ catheters are widely used in paediatric patients, 
Table 1 Characteristics of the patients studied

\begin{tabular}{|c|c|}
\hline Characteristic & Number $(\%)$ \\
\hline \multicolumn{2}{|l|}{$\operatorname{Sex}$} \\
\hline Male & $311(59.6 \%)$ \\
\hline Female & $211(40.4 \%)$ \\
\hline \multicolumn{2}{|l|}{ Age (years) } \\
\hline $18-39$ & $16(3.1 \%)$ \\
\hline $40-65$ & $204(39.1 \%)$ \\
\hline $65+$ & $302(57.8 \%)$ \\
\hline \multicolumn{2}{|l|}{ ICD-10 diagnoses } \\
\hline C00-C14 lips, oral cavity, pharynx & $86(16.5 \%)$ \\
\hline $\mathrm{C} 15-\mathrm{C} 26$ digestive organs & $265(50.8 \%)$ \\
\hline C30-C39 respiratory system and intrathoracic organs & $47(9.0 \%)$ \\
\hline C43-C44 skin & $2(0.4 \%)$ \\
\hline C50 mammary gland & $2(0.4 \%)$ \\
\hline C51-C58 female genitalia & $59(11.3 \%)$ \\
\hline C64-C68 urinary organs & $6(1.1 \%)$ \\
\hline C69-C72 central nervous system, eyes & $6(1.1 \%)$ \\
\hline C73-C75 thyroid and other endocrine glands & $2(0.4 \%)$ \\
\hline C76-C80 malignant neoplasms of ill-defined, other secondary and unspecified sites & $45(8.6 \%)$ \\
\hline C81-C96 malignant neoplasms of lymphoid, haematopoietic and related tissue & $2(0.4 \%)$ \\
\hline \multicolumn{2}{|l|}{ ECOG-performance status* } \\
\hline 0 & $281(53.8 \%)$ \\
\hline 1 & $208(39.8 \%)$ \\
\hline 2 & $28(5.4 \%)$ \\
\hline 3 & $4(0.8 \%)$ \\
\hline 4 & $1(0.2 \%)$ \\
\hline \multicolumn{2}{|l|}{ T-stage** } \\
\hline 1 & $55(10.5 \%)$ \\
\hline 2 & $107(20.5 \%)$ \\
\hline 3 & $193(37.0 \%)$ \\
\hline 4 & $119(22.8 \%)$ \\
\hline $\mathrm{N} / \mathrm{S}$ & $48(9.2 \%)$ \\
\hline \multicolumn{2}{|l|}{$N$-stage $* * *$} \\
\hline 0 & $131(25.1 \%)$ \\
\hline $1+$ & $333(63.8 \%)$ \\
\hline $\mathrm{N} / \mathrm{S}$ & $58(11.1 \%)$ \\
\hline \multicolumn{2}{|l|}{ Treatment strategy } \\
\hline Neoadjuvant & $150(28.7 \%)$ \\
\hline Adjuvant & $199(38.1 \%)$ \\
\hline Definitive & $173(33.1 \%)$ \\
\hline \multicolumn{2}{|l|}{ Intent-to-treat $* * * *$} \\
\hline Curative & $395(75.7 \%)$ \\
\hline Palliative & $127(24.3 \%)$ \\
\hline
\end{tabular}

*ECOG performance status: Activity status to estimate general condition of oncological patients. The scale ranges from 0 (unimpaired activity) to 5 (death) [40]

**T-stage (tumour): extension and behaviour of the primary tumour

***N-stage (nodule): lack or presence of regional lymph node metastases

****Initial intent to treat, without consideration of the actual outcome
Table 2 Complication frequency in relation to use

\begin{tabular}{llc}
\hline Use & Frequency of use & Complication rate \\
\hline Exclusively for chemotherapy & $360(69 \%)$ & $38(7.3 \%)$ \\
Exclusively for immunotherapy & $31(5.9 \%)$ & $12(2.3 \%)$ \\
Exclusively for parenteral feeding & $42(8.0 \%)$ & $8(1.5 \%)$ \\
Chemotherapy and parenteral feeding & $51(9.8 \%)$ & $9(1.7 \%)$ \\
Immunotherapy and parenteral feeding & $16(3.1 \%)$ & $3(0.6 \%)$ \\
Other & $22(4.2 \%)$ & $5(1.0 \%)$ \\
Overall & 522 & $75(14.4 \%)$ \\
\hline
\end{tabular}




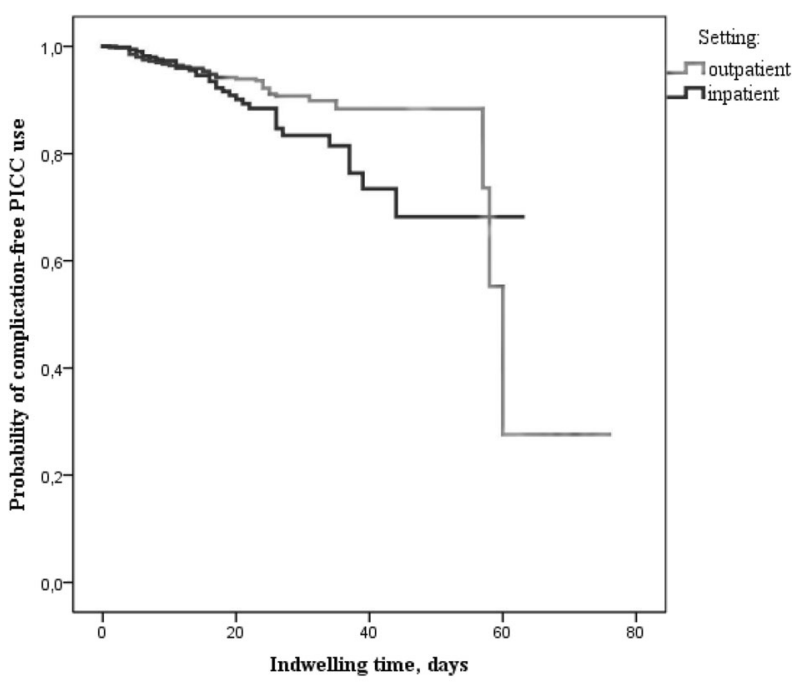

Number at risk

$\begin{array}{lllll}\text { outpatient } & 522 & 318 & 26 & 1\end{array}$

inpatient $\quad 522 \quad 120 \quad 20 \quad 2$

Fig. 1 Likelihood of a complication-free PICC use

whereas Groshong® and Broviac® catheters are common in adults undergoing haematopoietic stem cell transplantation or for home parenteral nutrition [20].

The use of non-tunnelled CVC as short-term access is limited to hospitalized patients and cannot be utilized in outpatient setting. It should stay in situ for no longer than 14 days to avoid complications $[13,14]$. We would like express our fundamental misgiving in relation to frequent CVC placements because of insertion risk and patients stress.

Implantable port (chest-port, groin-port or upper-limb-port (PICC-port)) is suggested as permanent venous access requiring a minor surgery for placement. They are not appropriate for use $<30$ days [13]. There is mostly no compelling need for them during standard radiation oncology protocols $<60$ days either.
The indication for the port system in the context of long-term multimodal therapy concepts should be made individually. In this regard, the PICC can be deployed with much more temporal flexibility, from a few weeks up to 6 months $[2,3,14,15]$.

A significant advantage of PICC over the port and tunnelled CVC is the low risk of procedure-related trauma, low risk of significant bleeding and easy to achieve local haemostasis even in a state of poor coagulation $[15,21]$.

The maintenance of PICC is simple; it requires only a professional competence in dealing with central venous catheters but no special training. Even a proportion of patients can be responsible for their own PICC care when discharged from hospital in between treatment regimens. The maintenance procedure is not demanding and stress-free because it is not associated with an invasive port chamber puncture [12].

The PICC removal is simple and can be quickly performed even by nurses. On the contrary, tunnelled CVC and portrelated complications require a surgery for revision or explantation [22, 23].

PICC has many decisive advantages over other venous access types, but it has not been established on a nationwide basis because of various arguable reasons until now.

The German Commission for Hospital Hygiene and Infection Prevention [Kommission für Krankenhaushygiene und Infektionsprävention, KRINKO] negatively appraises PICCs as the preferred central venous access. These concerns arise from studies conducted on critically ill patients on ICU wards [24-27]. The insights however are probably not valid in other (e.g. cancer) patient groups.

One of the most frequent, clinically relevant complications of all types of intravascular devices (IVD) is bloodstream infections (BSI). The incidence rates of IVD-related BSI are lowest with ports (0.1-0.2 per 1000 catheter-days), the highest with nontunnelled CVCs (2.3-2.7 per 1000 catheter days); PICCs show an intermediate risk profile (0.4-2.1 per 1000 catheter days) [24, 28, 29].

Table 3 Types of complications and their frequency

\begin{tabular}{llll}
\hline Type of complication & $\begin{array}{l}\text { Total frequency } \mathrm{n}(\%) \\
\text { [per 1000 catheter days] }\end{array}$ & $\begin{array}{l}\text { Outpatient frequency n (\%) } \\
\text { [per 1000 catheter days] }\end{array}$ & $\begin{array}{l}\text { Inpatient frequency n (\%) } \\
\text { [per 1000 catheter days] }\end{array}$ \\
\hline Local inflammation & $23(4.4 \%)[1.26]$ & $13(2.5 \%)[1.26]$ & $10(1.9 \%)[1.26]$ \\
Bloodstream infection & $11(2.1 \%)[0.60]$ & $2(0.4 \%)[0.19]$ & $9(1.7 \%)[1.13]$ \\
Occlusion & $11(2.1 \%)[0.60]$ & $6(1.1 \%)[0.58]$ & $5(1.0 \%)[0.63]$ \\
Dislocation & $6(1.1 \%)[0.33]$ & $2(0.4 \%)[0.19]$ & $4(0.8 \%)[0.50]$ \\
Deep vein thrombosis & $15(2.9 \%)[0.82]$ & $9(1.7 \%)[0.87]$ & $6(1.1 \%)[0.75]$ \\
Local bleeding & $1(0.2 \%)[0.05]$ & 0 & $1(0.2 \%)[0.13]$ \\
Septic thrombosis & $2(0.4 \%)[0.11]$ & $1(0.2 \%)[0.10]$ & $1(0.2 \%)[0.13]$ \\
Pulmonary artery embolism & $1(0.2 \%)[0.05]$ & $1(0.2 \%)[0.10]$ & 0 \\
Local allergic reaction & $1(0.2 \%)[0.05]$ & $1(0.2 \%)[0.10]$ & 0 \\
Accidental dislocation & $4(0.8 \%)[0.22]$ & $2(0.4 \%)[0.19]$ & $2(0.4 \%)[0.25]$ \\
Overall & $75(14.4 \%)[4.10]$ & $37(7.1 \%)[3.58]$ & $38(7.3 \%)[4.78]$ \\
\hline
\end{tabular}


Irrespective the site of port placement, chest or upper limb, there is an identical risk of infectious complications [30]. The incidence of BSI in tunnelled CVC $(1,8-7,9$ per 1000 catheter days) is highly dependent on study population and CVC usage [31]. The highest complications were observed in immunocompromised hosts.

In our cohort, the overall rate of PICC bloodstream infections was 0.6 per 1000 catheter days, thus comparable to the rate reported previously.

Consistent with observations by Maki et al., bloodstream infections occurred less frequently 0.2 per 1000 catheter days in the outpatient setting, than in the hospitalized patients 1.2 per 1000 catheter days [24]. A lower risk of BSI in ambulant patients can be due a less frequent and in general different use of IVD. It suggests a favourable safety profile of PICC for the outpatient setting. However, the assessment of a bloodstream infection was determined clinically. In case of suspected BSI, the PICC was removed immediately. Most of the investigated blood cultures and catheter tips remained without microbiological pathogen detection. We can report detection of Staphylococcus aureus in two blood cultures.

The incidence of a local or systemic catheter-related thrombotic complication depends upon the IVD type, insertion site, diameter of the vessel, thrombophilia, criteria for diagnosis, etc. The highest reported incidence of thrombosis was therefore observed in critically ill patients, in individuals with prior thrombotic events, active tumour disease and systemic inflammation accompanied by leucocytosis $>12 \mathrm{Gpt} / 1$ [7, 32-34]. These risk factors were present in our cancer patients to certain extent as well. We did not perform thrombosis prophylaxis routinely.

The risk of thrombotic event occurrence varies amongst different cancer entities. The highest rates have been observed in malignancies of the pancreas, brain and stomach $[35,36]$. Kidney, uterus, bladder, lung, colon [35] as well as hematologic malignancies are associated with relatively high risk of thrombosis [37]. Lower risk of thrombotic event is suspected for patients with breast, head and neck or prostate cancer [37, 38]. Especially in the treatment of lung, mediastinal, head and neck cancer, the radiation field can involve the PICC and the corresponding venous vessel. Apparently the radiation beam itself can have thrombogenic effects on vessels [39]. It is not clear whether the accumulation of local thrombogenic factors in this patient group results in a higher rate of PICC-associated thrombosis.

A significant part of PICCs in our cohort $(n=237,45,4 \%)$ was anatomically involved in to the radiation field ("head and neck cancer" $n=132$; "oesophageal tumours" $n=77$, "lung cancer/thoracic tumors" $n=28$ ). This circumstance did not statistically increase the rate of local thrombotic events ( $p=$ $0,722)$. The greatest part $(n=10)$ of PICCs removed due to venous thrombosis was not situated in the radiation beam. The thrombogenic effect of the radiation to the venous vessel may be low and thus statistically not apparent. In our opinion, no change of clinical routine in placing PICCs in regard to a possible radiation field is needed.

In previous studies, PICC placement was associated with a greater risk of deep vein thrombosis (DVT) (OR $0.43 ; 95 \%$ CI $0.23-0.80$ ) than ports 0.11 per 1000 catheter days $[7,28,40]$. The incidence of thrombotic complication for PICC varies between 5 and $15 \%$ for hospitalized patients and between 2 and $5 \%$ for ambulatory patients [41].

The incidence of thrombosis observed in our patients $2.8 \%$ ( 0.82 per 1000 catheter days) corresponds to that evidence.

As with all centrally inserted catheters, the incidence of thrombosis increases depending on the effective catheter diameter and thus the number of lumens used [7, 32, 42]. Double lumen PICCs were fully sufficient in our radiooncologic patients; we routinely used only this PICC type.

As DVT is common in PICC, benefit risk profile assessment should be performed individually. The clinical situation and the patient's needs should be examined and considered to provide an optimal therapy on the one hand but also minimize the risk of thrombosis on the other hand.

The most cases of PICC-associated DVT diagnosed clinically due to lacking duplex sonographic verification, which was not logistically available. One prospective study found that $75 \%$ of patients identified with DVT were asymptomatic [43]. That is why a higher thrombosis incidence in our cohort can be suspected. The prognostic meaning and the outcome of such occult undiagnosed DVTs remain unclear. Although the PICC does not necessarily have to be removed when detecting a thrombosis, we never left it in situ if this complication was suspected. Ultimately, it could have continued to be used if patency and no infection were assumed [44].

In our analysis, multivariate logistic regression found the immunotherapy with cetuximab and was an independent risk factor for PICC-related complications. Out of 31 patients who received the immunotherapy, 9 developed inflammation at the catheter exit site. Common side effects with cetuximab include disseminated erythema, acneiform rashes and local superinfections [45]. These cutaneous side effects are mediated via the EGF receptor of the skin and hair follicles. It is possible that the increased incidence of local skin reactions at the PICC exit site in patients receiving cetuximab therapy can be explained by this aetiological mechanism. The recommendations for the management of cutaneous side effects of immunotherapy are not designed to address local complications at the catheter exit sites and are, therefore, not transferable to them.

The therapeutic regimen of thoracic, ENT (ear-nose-throat) and mediastinal cancer patients regularly include the irradiation of the supraclavicular or cervical lymph node regions in combination with systemically applied chemotherapy or immunotherapy. CVCs and ports inserted into the jugular and subclavian veins, as well as associated dressings can interfere with the irradiation fields. Other possible complication is a pronounced radiodermatitis with skin desquamation and 
superinfection. In such situations, a PICC or PICC-port placed on the upper arm, hence outside the irradiation field, is a very good alternative to manage the treatment successfully.

The main limitation of our study is not only the retrospective data assessment but also the subjectivity of clinical decisions made in particular patient. All patients were treated by a doctor team. The amount of documented complications, the appraisal of their severity and particular their management were dependent on the percepted clinical context, doctor's qualification and expertise, as well the on patient factors. Wishing to minimize PICC associated risks especially in ambulant patients, we removed the culprit IVD on a suspicion of complication generously. This corresponds to a very conservative and defensive PICC management, which leads to statistically elevated complication rate. To realize a more liberal management, a practical experience gain in dealing with the PICC on both the medical and nursing sides (nursing services, general practitioners) is needed.

In summary, PICCs represent a safe alternative to the port system implantation in cancer patients receiving radiotherapy and maintaining the venous access for repeated admissions on out- or inpatient basis from weeks to a maximum of 6 months.

Author contributions Ulf Teichgräber and Dorothea Mielke are responsible for study conception and design and analysis and interpretation of data. All authors drafted or revised the manuscript, have read and approved its final version, and are accountable for all aspects of the paper.

Funding Information Open Access funding provided by Projekt DEAL.

\section{Compliance with ethical standards}

Conflict of interest The study was financed by the budgetary resources of the department of radiology, University Hospital Jena, Germany. The study was neither funded nor sponsored by a third party.

Open Access This article is licensed under a Creative Commons Attribution 4.0 International License, which permits use, sharing, adaptation, distribution and reproduction in any medium or format, as long as you give appropriate credit to the original author(s) and the source, provide a link to the Creative Commons licence, and indicate if changes were made. The images or other third party material in this article are included in the article's Creative Commons licence, unless indicated otherwise in a credit line to the material. If material is not included in the article's Creative Commons licence and your intended use is not permitted by statutory regulation or exceeds the permitted use, you will need to obtain permission directly from the copyright holder. To view a copy of this licence, visit http://creativecommons.org/licenses/by/4.0/.

\section{References}

1. Matsuzaki A, Suminoe A, Koga Y, Hatano M, Hattori S, Hara T (2006) Long-term use of peripherally inserted central venous catheters for cancer chemotherapy in children. Support Care Cancer 14(2):153-160. https://doi.org/10.1007/s00520-005-0848-x

2. Hans M (2017) Pflegeleitfaden PICC-Line. http://radiologie. charite.de/pflegeleitfaden/
3. Hatakeyama N, Hori T, Yamamoto M, Mizue N, Inazawa N, Igarashi K, Tsutsumi H, Suzuki N (2011) An evaluation of peripherally inserted central venous catheters for children with cancer requiring long-term venous access. Int J Hematol 94(4):372-377. https://doi.org/10.1007/s12185-011-0928-2

4. Hoshal VL Jr (1975) Total intravenous nutrition with peripherally inserted silicone elastomer central venous catheters. Arch Surg 110(5):644-646

5. MacDonald AS, Master SK, Moffitt EA (1977) A comparative study of peripherally inserted silicone catheters for parenteral nutrition. Can Anaesth Soc J 24(2):263-269

6. Menendez JJ, Verdu C, Calderon B, Gomez-Zamora A, Schuffelmann C, de la Cruz JJ, de la Oliva P (2016) Incidence and risk factors of superficial and deep vein thrombosis associated with peripherally inserted central catheters in children. J Thromb Haemost 14(11):2158-2168. https://doi.org/10.1111/jth.13478

7. Chopra V, Anand S, Hickner A, Buist M, Rogers MA, Saint S, Flanders SA (2013) Risk of venous thromboembolism associated with peripherally inserted central catheters: a systematic review and meta-analysis. Lancet 382(9889):311-325. https://doi.org/10.1016/ S0140-6736(13)60592-9

8. Ho C, Spry C (2017) CADTH rapid response reports. In: central venous access devices (CVADs) and peripherally inserted central catheters (PICCs) for adult and pediatric patients: a review of clinical effectiveness and safety. Canadian Agency for Drugs and Technologies in health copyright (c) 2017 Canadian Agency for Drugs and Technologies in health., Ottawa (ON),

9. Cotogni P, Pittiruti M (2014) Focus on peripherally inserted central catheters in critically ill patients. World J Crit Care Med 3(4):80-94. https://doi.org/10.5492/wjccm.v3.i4.80

10. Fearonce G, Faraklas I, Saffle JR, Cochran A (2010) Peripherally inserted central venous catheters and central venous catheters in burn patients: a comparative review. J Burn Care Res 31(1):3135. https://doi.org/10.1097/BCR.0b013e3181cb8eaa

11. Yamaguchi RS, Noritomi DT, Degaspare NV, Munoz GOC, Porto APM, Costa SF, Ranzani OT (2017) Peripherally inserted central catheters are associated with lower risk of bloodstream infection compared with central venous catheters in paediatric intensive care patients: a propensity-adjusted analysis. Intensive Care Med 43(8): 1097-1104. https://doi.org/10.1007/s00134-017-4852-7

12. Teichgräber UK, Pfitzmann R, Hofmann HAF (2011) Portsysteme als integraler Bestandteil von Chemotherapien. Dtsch Arztebl Int 108(9):147-154. https://doi.org/10.3238/arztebl.2011.0147

13. Chopra V, Flanders SA, Saint S, Woller SC, O'Grady NP, Safdar N, Trerotola SO, Saran R, Moureau N, Wiseman S, Pittiruti M, Akl EA, Lee AY, Courey A, Swaminathan L, LeDonne J, Becker C, Krein SL, Bernstein SJ, Michigan Appropriateness Guide for Intravenouse Catheters P (2015) The Michigan appropriateness guide for intravenous catheters (MAGIC): results from a multispecialty panel using the RAND/UCLA appropriateness method. Ann Intern Med 163(6 Suppl):S1-S40. https://doi.org/10.7326/M15-0744

14. Gebauer B, Beck A, Wagner HJ (2008) Zentralvenöse Katheter: Diagnostik von Komplikationen und therapeutische Optionen. Radiologie up2date 8(02):135-154. https://doi.org/10.1055/s2007-995703

15. Gebauer B, Teichgraber UK, Podrabsky P, Beck A, Wagner HJ (2004) Ultrasound- and fluoroscopy-guided implantation of peripherally inserted central venous catheters (PICCs). Rofo 176(3):386391. https://doi.org/10.1055/s-2004-812737

16. Gorski LA (2017) The 2016 infusion therapy standards of practice. Home Healthcare Now 35(1):10-18. https://doi.org/10.1097/nhh. 0000000000000481

17. Cho CH, Schlattmann P, Nagel S, Schmittbuttner N, Hartung F, Teichgraber UK (2018) Cephalad dislocation of PICCs under different upper limb positions: influence of age, gender, BMI, number 
of lumens. J Vasc Access 19(2):141-145. https://doi.org/10.5301/ jva.5000809

18. Bertoglio S, Solari N, Meszaros P, Vassallo F, Bonvento M, Pastorino S, Bruzzi P (2012) Efficacy of normal saline versus heparinized saline solution for locking catheters of totally implantable long-term central vascular access devices in adult cancer patients. Cancer Nurs 35(4):E35-E42. https://doi.org/10.1097/NCC. 0b013e31823312b1

19. O'Grady NP, Alexander M, Burns LA, Dellinger EP, Garland J, Heard SO, Lipsett PA, Masur H, Mermel LA, Pearson ML, Raad II, Randolph AG, Rupp ME, Saint S, Healthcare Infection Control Practices Advisory C (2011) Guidelines for the prevention of intravascular catheter-related infections. Am J Infect Control 39(4 Suppl 1):S1-S34. https://doi.org/10.1016/j.ajic.2011.01.003

20. Partiell implantierte zentralvenöse Katheter (2015) Onkopedia. https://www.onkopedia.com/de/onkopedia-p/guidelines/partiellimplantierte-zentralvenoese-katheter/@ @ guideline/html/index.html

21. Hoch JR (1997) Management of the complications of long-term venous access. Semin Vasc Surg 10(3):135-143

22. Kausche S, Nagel SN, Teichgraber U (2011) Interventional radiological imaging and treatment of port catheter dysfunctions. Rofo 183(3):260-266. https://doi.org/10.1055/s-0029-1245879

23. Sousa B, Furlanetto J, Hutka M, Gouveia P, Wuerstlein R, Mariz JM, Pinto D, Cardoso F, Committee EG (2015) Central venous access in oncology: ESMO clinical practice guidelines. Ann Oncol 26(Suppl 5): v152-v168. https://doi.org/10.1093/annonc/mdv296

24. Maki DG, Kluger DM, Crnich CJ (2006) The risk of bloodstream infection in adults with different intravascular devices: a systematic review of 200 published prospective studies. Mayo Clin Proc 81(9): 1159-1171. https://doi.org/10.4065/81.9.1159

25. Safdar N, Maki DG (2005) Risk of catheter-related bloodstream infection with peripherally inserted central venous catheters used in hospitalized patients. Chest 128(2):489-495. https://doi.org/10. 1378/chest.128.2.489

26. Chopra V, Anand S, Krein SL, Chenoweth C, Saint S (2012) Bloodstream infection, venous thrombosis, and peripherally inserted central catheters: reappraising the evidence. Am J Med 125(8):733-741. https://doi.org/10.1016/j.amjmed.2012.04.010

27. Chopra V, O'Horo JC, Rogers MA, Maki DG, Safdar N (2013) The risk of bloodstream infection associated with peripherally inserted central catheters compared with central venous catheters in adults: a systematic review and meta-analysis. Infect Control Hosp Epidemiol 34(9):908-918. https://doi.org/10.1086/671737

28. Teichgraber UK, Kausche S, Nagel SN, Gebauer B (2011) Outcome analysis in 3,160 implantations of radiologically guided placements of totally implantable central venous port systems. Eur Radiol 21(6): 1224-1232. https://doi.org/10.1007/s00330-010-2045-7

29. Kluger DM, Maki DG (1999) The relative risk of intravascular device-related bloodstream infections with different types of intravascular devices in adults: a meta-analysis of 206 published studies (abstract). Infect Control Hosp Epidemiol 21:95-96. https://doi.org/ 10.1017/S0195941700072866

30. Fonseca IY, Krutman M, Nishinari K, Yazbek G, Teivelis MP, Bomfim GA, Cavalcante RN, Wolosker N (2016) Brachial insertion of fully implantable venous catheters for chemotherapy: complications and quality of life assessment in 35 patients. Einstein (Sao Paulo) 14(4):473-479. https://doi.org/10.1590/S167945082016AO3606

31. Elishoov H, Or R, Strauss N, Engelhard D (1998) Nosocomial colonization, septicemia, and Hickman/Broviac catheter-related infections in bone marrow transplant recipients. A 5-year prospective study. Medicine (Baltimore) 77(2):83-101. https://doi.org/10.1097/ 00005792-199803000-00002

32. Chopra V, Kaatz S, Conlon A, Paje D, Grant PJ, Rogers MAM, Bernstein SJ, Saint S, Flanders SA (2017) The Michigan risk score to predict peripherally inserted central catheter-associated thrombosis. J Thromb Haemost 15(10):1951-1962. https://doi. org/10.1111/jth. 13794

33. Lee AY, Levine MN (2003) Venous thromboembolism and cancer: risks and outcomes. Circulation 107(23 Suppl 1):I17-I21. https:// doi.org/10.1161/01.CIR.0000078466.72504.AC

34. Blom JW, Vanderschoot JP, Oostindier MJ, Osanto S, van der Meer FJ, Rosendaal FR (2006) Incidence of venous thrombosis in a large cohort of 66,329 cancer patients: results of a record linkage study. J Thromb Haemost 4(3):529-535. https://doi.org/10.1111/j.15387836.2006.01804.x

35. Chew HK, Wun T, Harvey D, Zhou H, White RH (2006) Incidence of venous thromboembolism and its effect on survival among patients with common cancers. JAMA Intern Med 166(4):458-464. https://doi.org/10.1001/archinte.166.4.458

36. Wun T, White RH (2009) Epidemiology of cancer-related venous thromboembolism. Best Pract Res Clin Haematol 22(1):9-23. https://doi.org/10.1016/j.beha.2008.12.001

37. Blom JW, Doggen CJM, Osanto S, Rosendaal FR (2005) Malignancies, Prothrombotic mutations, and the risk of venous thrombosis. JAMA 293(6):715-722. https://doi.org/10.1001/jama. 293.6.715

38. Haen P, Mege D, Crescence L, Dignat-George F, Dubois C, Panicot-Dubois L (2019) Thrombosis risk associated with head and neck cancer: a review. Int J Mol Sci 20(11):2838. https://doi. org/10.3390/ijms20112838

39. Guy J-B, Bertoletti L, Magné N, Rancoule C, Mahé I, Font C, Sanz O, Martín-Antorán JM, Pace F, Vela JR, Monreal M (2017) Venous thromboembolism in radiation therapy cancer patients: findings from the RIETE registry. Crit Rev Oncol Hematol 113:83-89. https://doi.org/10.1016/j.critrevonc.2017.03.006

40. Saber W, Moua T, Williams EC, Verso M, Agnelli G, Couban S, Young A, De Cicco M, Biffi R, van Rooden CJ, Huisman MV, Fagnani D, Cimminiello C, Moia M, Magagnoli M, Povoski SP, Malak SF, Lee AY (2011) Risk factors for catheter-related thrombosis (CRT) in cancer patients: a patient-level data (IPD) meta-analysis of clinical trials and prospective studies. J Thromb Haemost 9(2):312319. https://doi.org/10.1111/j.1538-7836.2010.04126.x

41. Fallouh N, McGuirk HM, Flanders SA, Chopra V (2015) Peripherally inserted central catheter-associated deep vein thrombosis: a narrative review. Am J Med 128(7):722-738. https://doi. org/10.1016/j.amjmed.2015.01.027

42. Evans RS, Sharp JH, Linford LH, Lloyd JF, Tripp JS, Jones JP, Woller SC, Stevens SM, Elliott CG, Weaver LK (2010) Risk of symptomatic DVT associated with peripherally inserted central catheters. Chest 138(4):803-810. https://doi.org/10.1378/chest.10-0154

43. Luciani A, Clement O, Halimi P, Goudot D, Portier F, Bassot V, Luciani JA, Avan P, Frija G, Bonfils P (2001) Catheter-related upper extremity deep venous thrombosis in cancer patients: a prospective study based on Doppler US. Radiology 220(3):655-660. https://doi.org/10.1148/radiol.2203001181

44. S2-Leitlinie: Diagnostik und Therapie der Venenthrombose und der Lungenembolie (2015) Arbeitsgemeinschaft der Wissenschaftlichen Medizinischen Fachgesellschaften Register $\mathrm{Nr}$ 065/002. http://www.awmf.org/uploads/tx szleitlinien/065-0021 S2k VTE 2016-01.pdf

45. Habl G, Potthoff K, Haefner MF, Abdollahi A, Hassel JC, Boller E, Indorf M, Debus J (2013) Differentiation of irradiation and cetuximab induced skin reactions in patients with locally advanced head and neck cancer undergoing radioimmunotherapy: the HICARE protocol (head and neck cancer: immunochemo and radiotherapy with erbitux) - a multicenter phase IV trial. BMC Cancer 13:345. https://doi.org/10.1186/1471-2407-13-345

Publisher's note Springer Nature remains neutral with regard to jurisdictional claims in published maps and institutional affiliations. 